\title{
Recuperando la memoria perdida: esclavitud y libertad en El barco de ébano*
}

\author{
Martha Ojeda $^{1}$ \\ Transylvania University, (Estados Unidos) \\ ORCID: 0000-0002-9396-2238
}

Recibido: 30 de enero de 2019

Aceptado: 19 de marzo de 2019

\section{Resumen}

Este estudio tiene un doble propósito: por una parte, analizar brevemente la representación de la esclavitud en El barco de ébano (2008), de Ricardo Gattini, durante en el periodo colonial tardío en la Capitanía de Chile y las maneras en que la novela reinscribe la presencia afrochilena en ese periodo. Por otra parte, se propone hacer reflexión crítica en torno al discurso racializado en la representación de las mujeres negras esclavas y su posicionalidad como sujeto esclavizado en El barco de ébano. Analizaremos el papel de Petra (la esclava etíope) y su función dentro de la novela para esclarecer algunas estrategias narrativas y discursivas que revelan la ideología racializada de su momento histórico. Los imagina-

\section{Abstract}

This study has two main goals: on the one hand, to briefly analyze the representation of slavery in Ricardo Gattini's El barco de ébano (2008), during the late colonial period in the General Captaincy of Chile, and the ways in which the novel reinscribes the Afro-Chilean presence during those times. On the other hand, it seeks to reflect critically on the racialized discourse in the representation of black slave women and their positionality as enslaved subjects in El barco de ébano. We will analyze the role of Petra (the Ethiopian slave) within the novel to clarify some narrative and discursive strategies that reveal a racialized ideology of its times. The national imaginaries have helped to create

\footnotetext{
* Recovering memory loss: freedom and slavery in El barco de ébano

1 Doctora en Literatura Latinoamericana por la Universidad de Kentucky (EE.UU.), Profesora titular del Programa de Lenguas Extranjeras de la Transylvania University (EE.UU.). Correo: mojeda@transy.edu
} 
rios nacionales han contribuido a crear e implementar políticas decisivas de omisión que han tenido un impacto directo en la exclusión de algunos grupos étnicos en la forja de la nación. A la luz de esta realidad, y pese a las contradicciones, vacilaciones, $\mathrm{y}$ paradojas notadas en el tejido narrativo, la novela de Gattini es de importancia capital, porque representa una tentativa de revisión historiográfica y pone de relieve la imperante necesidad de recuperar la memoria perdida y/o negada, un hecho largamente postergado por la historiografía local.

Palabras clave: Afro-chilenos, la esclavitud en Chile, literatura afrolatina, mujeres esclavas, novela histórica and implement decisive policies of omission that have had a direct impact on the exclusion of some ethnic groups in the creation of nationhood. In light of this reality, and despite the contradictions, and paradoxes noted in the text, Gattini's novel is of great importance, because it represents an attempt at historiographical revision, and it highlights the pressing need to recover the lost or repressed memory, which has been postponed for a long time by local historiography.

Keywords: Afro-Chileans, Slavery in Chile, Afro-latino literature, women slaves, historical novel

\section{Introducción}

El barco de ébano (2008), de Ricardo Gattini, es la primera novela histórica chilena que tiene como tema central el tráfico de esclavos negros a la Capitanía de Chile ${ }^{2}$.La meta principal de Gattini era recuperar la memoria perdida u olvidada de la historia chilena que, hasta ese momento, había permanecido poco investigada. Mientras que en Perú, Colombia, y Ecuador los estudios en el campo de la cultura y literatura afrohispanas se vienen realizando hace algunas décadas, en Chile empiezan a realizarse con mayor frecuencia en años recientes, socavando, así, su imagen como país de herencia predominantemente europea.

Al hacer un repaso de los estudios de principios del siglo XXI sobre la presencia negra en Chile, se ponen en evidencia la invisibilización

2 En mayo del 2018, aparece una nueva edición de la novela (en versión digital) con una cubierta diferente. Esta tiene la imagen de un barco negrero en alta mar, superpuesta de la cara de una mujer negra. 
y la borradura de los afrochilenos de la historia oficial. Una de las razones de dicho ocultamiento sería que, admitir la existencia de esclavitud negra en la capitanía del Sur, atentaría contra la imagen de la identidad nacional chilena como país "moderno y progresista", una imagen diseminada y afianzada desde el siglo XIX ${ }^{3}$. Sin embargo, este discurso que trataba de borrar la presencia afrochilena de la identidad nacional empieza a resquebrajarse con el estudio seminal de Rolando Mellafe, La introducción de la esclavitud negra en Chile. Tráfico y rutas (1959), que fue por mucho tiempo la única obra de gran envergadura sobre este tema y es uno de los pocos trabajos de investigación de su época que presenta la historia oficial de la esclavitud negroafricana en el periodo colonial. En años más recientes, las investigaciones de historiadores han prestado particular atención al tema y han publicado múltiples artículos y libros que dan cuenta de una presencia afrochilena pujante, especialmente en el período colonial tardío. Es el caso de Celia Cussen, Huellas de Africa en América: Perspectivas para Chile (2009); María Teresa Contreras Segura, "Una ausencia aparente. Africanos y afromestizos en Valparaíso tardocolonial. 1170-1820"; William San Martin, "Esclavitud, libertades y resistencias. Hacia una propuesta integrativa a las condiciones de la negritud en Chile, S. XVIII"; y Paulina Barrenechea, "Patrimonio, narrativas racializadas y políticas de la memoria. Abordaje a un manuscrito afrodescendiente en el Valle de Azapa", en el campo de la literatura. Otro aporte significativo y clave que contribuye a la recuperación del legado afrochileno "desde adentro", es Lumbanga: memorias orales de la cultura afrochilena (2010) de Cristian Báez. Asimismo, Marta Salgado, una de las fundadoras de la ONG Oro Negro, publica Afrochilenos: una historia oculta (2013). Los estudiosos como Báez y Salgado hurgan en la historia no oficial, en una suerte de intrahistoria, es decir, en la documentación epistolar, en manuscritos de testimonios narrativos personales, en testamentos, en registros parroquiales, y en memorias orales para develar el submundo de la sociedad colonial chilena ${ }^{4}$. Dichos documentos abren una ventana a esas otras historias que han sido borradas, y ocultadas de la historiografía oficial o, como diría Paulina Barrenechea, "aquellas subjetividades obliteradas por el relato nacional chileno" (2015: 15) que son poco conocidas y escasamente integradas.

3 Para un análisis detallado de este fenómeno véase, "Afrochilenos: Discursos oficiales en torno a los afromestizos en Chile" de Fernanda del Rio Ortiz.

4 Un ejemplo clave es el caso del manuscrito estudiado por Paulina Barrenechea sobre los afrodescendientes en el valle de Azapa (2017). Véase también el estudio de Rosario Márquez y Ma Luisa Candau sobre las "Otras mujeres de América: las esclavas negras en tiempos de la Colonia. Un estudio a través de la correspondencia privada" (2016). 
Este estudio tiene un doble propósito: por una parte, analizar brevemente la representación de la esclavitud en El barco de ébano, lo cual implica explorar las maneras en que la novela reinscribe la presencia afrochilena en el periodo colonial tardío en la Capitanía de Chile y cómo representa los procesos de integración social que se forjan en Valparaíso. Para el análisis de lo antedicho, nos serviremos de los estudios sobre la memoria de Elizabeth Jelin quien, en Los trabajos de la memoria (2002), examina los procesos de preservación de la memoria social y /o colectiva, y el papel que juegan los aparatos institucionales para tratar de mantener u obliterar ciertas memorias. Por otra parte, nos proponemos hacer una reflexión crítica en torno al discurso racializado o "lenguaje impregnado de racismo" (Morrison, 1992: 12-13) en la representación de las mujeres negras esclavas y su posicionalidad como sujeto esclavizado en la novela de Gattini. Para ello, nos serviremos del estudio de Toni Morrison, Playing in the Dark: Whiteness and the Literary Imagination, donde formula preguntas incisivas sobre las maneras en que se representan a los personajes negros en la narrativa.

\section{Hurgar en el pasado: representaciones de la esclavitud, manumisión y los retos de la libertad}

El barco de ébano pone en escena una historia de amor al estilo de las obras románticas decimonónicas. Se sirve de la ficción (la relación entre el ebanista y la princesa etíope negra) como hilo conductor para explorar momentos históricos claves entre 1807 y 1837 en la Capitanía de Chile. La novela consta de 15 capítulos, y relata el último viaje de un barco negrero inglés, llamado Lancaster, desde la isla de Comoro hacia América. En el momento en que zarpa, en 1807, Inglaterra acaba de declarar la abolición de la trata, razón por la cual, el barco debe viajar bajo la bandera española y con el nombre de Pilar. La meta de la tripulación es desembarcar el "cargamento negro" en Montevideo y vender el barco en Buenos Aires por un mejor precio. El narrador describe la compra de esclavos en la isla de Comoro, la travesía y las condiciones insalubres en que viajan los 341 esclavos abordo ${ }^{5}$. Un sinfín de personajes históricos (O’Higgins, San Martín, gobernadores) desfilan por las páginas de la novela, pero el personaje central es el ebanista inglés, cuyo nombre nunca se nos revela. Los personajes secundarios son las tres mujeres negras, el

5 De los 341esclavos, sólo 328 llegan a Montevideo. Este número no incluye a las "piezas" que otros oficiales traen por su cuenta, entre las cuales se encuentran las tres mujeres negras (Gattini: 45). 
capitán Rhods, y el carpintero mayor Mc Andrew. Los personajes terciarios son los otros miembros de la tripulación, y los 341 esclavos. Entre éstos se distinguen tres mujeres negras inseparables que son tratadas de manera "especial" porque pertenecen al carpintero mayor. A una de esas esclavas se le conoce como la "dama tan" y hacia el final de la novela, aprendemos que se llama Petra y es una princesa etíope seleccionada especialmente para Mc Andrew.

El barco de ébano se abre con el asesinato enigmático de Mc Andrew $\mathrm{y}$, como resultado de su muerte, el ebanista -su ayudante- es nombrado su albacea para disponer de sus pertenencias, entre las cuales se hallan las tres esclavas negras. El primer encuentro del ebanista con la "dama tan" ocurre en el galpón de la isla de Comoro y es descrita como una revelación: "debió recuperarse de esa visión resplandeciente" y "se quedó demasiado tiempo con el aliento suspendido mirándola fijamente [...] sólo una inusual y extraordinaria belleza habría exaltado sus sentidos y logrado conmover su ánimo de hombre frío y pragmático" (pp. 13-14). El ebanista se enamora de la princesa etíope y no cumple con la disposición de venderla en Montevideo sino que decide continuar su viaje hacia Valparaíso donde ha oído que el trato a los esclavos es "más cálido y la manumisión era un acto frecuente" (p. 39) y cree que allí podrá forjar un futuro con dicha princesa ${ }^{6}$. El narrador nos relata la historia desde la perspectiva del ebanista quien, a lo largo de la novela, denuncia la esclavitud y el uso de seres humanos como mercancía.

En el capítulo doce, el tono de la narración es fuertemente anti-esclavista e inscribe una denuncia social y política del decreto de 1807 (La Ley de la Abolición de la trata) que termina con el tráfico negrero, pero no con la esclavitud:

Como las marcas de la viruela, todavía no se desprendía de los fundamentos que originaron la Inglaterra negrera. No les había enseñado a quemar las raíces de la esclavitud y, por otro lado, la intelectualidad inglesa pretendía negarla, desconocerla, conformarse sólo con la prohibición de su comercio, cegándose a la verdad por mano propia: la peor forma de perder la libertad de espíritu. Y algo más cruel: convencer al mundo que el problema ya estaba resuelto. (pp. 152-153. El énfasis es nuestro)

\footnotetext{
6 Aqui, Gattini perpetúa las creencias de que en Chile el trato a los esclavos era más benigno. Es interesante notar afirmaciones similares en otros estudiosos sobre la esclavitud en el Perú, por ejemplo. Da la impresión de que todos se disputan por ocupar el primer puesto en quién daba el trato más benigno a sus esclavos, como si esto les absolviera de la barbaridad de dicha práctica.
} 
Al comparar las consecuencias de la esclavitud con "marcas de la viruela", la novela hace hincapié en el carácter indeleble de una práctica que los intelectuales abolicionistas pretendían borrar y, peor aún, creer que el problema ya no existía. Dichas concepciones no se limitaron a Inglaterra, sino que también se arraigaron en el imaginario chileno. Es decir que estas ideas fueron diseminadas por medio de comerciantes y residentes ingleses que eran un contingente importante en el periodo colonial tardío. La novela de Gattini nos hace testigos de una sociedad en proceso de transición donde participan diversos grupos étnicos: ingleses, mapuches, negros esclavos, negros manumisos y mulatos libres. Al llegar a Valparaíso, y en cuanto tiene la oportunidad, el ebanista les da la libertad a Petra, Naha y Sinaya, quien tiene un hijo de su amo irlandés (Mc Andrews) como consecuencia de una violación:

No obstante, en un país donde la manumisión se había convertido en una práctica común, era habitual que sus esclavos así liberados se quedaran en la casa de sus ex amos. De hecho, Sinaya fue manumisa antes de Petra y Naha, cuando se bautizó a Junior, para determinar su registro de esa forma. Los libertos no tenían donde ir, se sentían solos e incapacitados para desenvolverse por sí mismos y de romper el antiguo lazo de dependencia. Pero él no tenía una solución para evitar esto último, dentro del mundo social que lo rodeaban y del cual ellas, pero también él, dependían (p. 124. El énfasis es nuestro)

El pasaje arriba citado es significativo y, a su vez, resume la ideología que permea y subyace en el texto narrativo. Se evidencia una suerte de tensión entre el deseo de condenar la esclavitud y de evitar la cosificación del sujeto esclavizado. Por el contrario, se le niega a éste el papel de agente de su libertad y de su propio destino, como diría Carlos Aguirre (1993). Los esclavos manumisos son descritos como incapaces de tomar las riendas de su destino ("se sentían incapacitados para desenvolverse por sí mismos"), pese a que los documentos históricos muestran su participación en un complejo entramado de relaciones sociales y, muchas veces, una participación activa en sus nuevas sociedades:

Los negros libres del Santiago colonial cuyos testamentos han sobrevivido se ganaron el pan en una variedad de labores. Los hubo zapateros como Marigorta, sastres, silleros, herreros, pulperos, o bodegueros, carpinteros, curtidores, e incluso prestamistas. Las negras libres trabajaban como costureras, parteras, y sirvientas; según 
documentos, una era zapatera y varias llegaros a ser propietarias de pulperías y bodegones (Cussen, 2009: 120).

Cabe notar la variedad de opciones que tenían los libertos para participar en diversos oficios que les permitían, eventualmente, reunir suficiente dinero para comprar su propia libertad. Celia Cussen, en "La ardua tarea de ser libre: Manumisión e integración social de los negros en Santiago de Chile colonial", subraya la complejidad de dicha práctica y el proceso de integración del esclavo negro chileno. Sirviéndose principalmente de documentos históricos como testamentos y algunas afiliaciones a las cofradías, pone en evidencia los complejos procesos y entramados sociales que caracterizaban el periodo colonial. No obstante, existe otro factor que no puede soslayarse, y es que la manumisión no implicaba la libertad inmediata ya que existían

[...] una serie de restricciones sociales y legales [que] regían las actividades de los ex esclavos y del conjunto de los afrodescendientes, limitando sus movimientos y sus oportunidades económicas, regulando sus costumbres y, en teoría (cuando no siempre en la práctica), obligándolos a morar en casa de un español y pagar tributo a la corona (Cussen, 2009: 116).

Sin embargo, la novela no señala que las dificultades de ser libres estuvieran ligadas a las limitaciones impuestas por los amos, sino que le quita agencia al ex esclavo y aún cuestiona su capacidad para comprender la importancia o significancia de su libertad. Los documentos a los que Cussen hace referencia datan del siglo XVI y XVII. Por eso, tal como señala investigadora, acerca de que "la autocompra fue el modo más común de obtener la libertad” (Cussen, 2009: 114), es plausible conjeturar que para el siglo XIX, época en que se desarrolla nuestra novela, ya existiera una red más amplia de sistemas de soporte y mayores probabilidades de auto compra. Entonces, el análisis de la representación de los manumisos en la novela de Gattini, cotejado con los documentos históricos oficiales y extra oficiales, nos permite construir una imagen más completa que da cuenta de la complejidad del camino a la libertad. El estudio de Jelin, Los trabajos de la memoria, nos brinda las herramientas para dilucidar cómo se construye la memoria a partir de reservorios pasivos: "rastros almacenados, saberes reconocibles, información archivada en la mente de las personas" (2002: 22), lo cual:

[...] permite tomar las memorias colectivas no sólo como datos "dados", sino también centrar la atención sobre 
los procesos de su construcción. Esto implica dar lugar a distintos actores sociales (inclusive a los marginados y excluidos) y a las disputas y negociaciones de sentidos del pasado en escenarios diversos (Pollak, 1989). También permite dejar abierta a la investigación empírica la existencia o no de memorias dominantes, hegemónicas, únicas u "oficiales". (Jelin, 2002: 22)

Esto puede ser sintomático de un momento coyuntural de la activación de ciertas memorias (la presencia de un componente africano en la identidad chilena) que a juicio de Silvia Valero, es representativa de una tendencia en las novelas latinoamericanas del siglo XXI que buscan reinscribir el tema 'afro' en la literatura (2015: 557-560).

Los registros históricos muestran que para el siglo XVIII (según el censo realizado en 1777-1778), el 10\% de la población chilena del Obispado de Santiago estaba compuesto por negros y mulatos (esclavos y libres) ${ }^{7}$. De entre ellos, un gran número de afrochilenos participaban activamente en la economía del país ya que muchos tenían oficios y algunos habían podido comprar su propia libertad. Entonces, llama la atención que la novela subraye el hecho de que "la manumisión se había convertido en una práctica común". A pesar de ello, el análisis discursivo no muestra personajes fuertes y soberanos que actúen como agentes activos en su nueva nación. Las investigaciones sobre los procesos de manumisión dan cuenta del papel de las cofradías como espacios de resistencia y liberación que posibilitaban el mutuo apoyo en la transición a la nueva condición de liberto. Según Cussen, "[...] la forma de asociación más común con la vida religiosa es la pertenencia a una cofradía. Un $40 \%$ de los testadores de este estudio declara pertenecer a una o más cofradías [...]" (2009: 126). Nuestra novela no representa a los negros manumisos insertados en la sociedad de Valparaíso sino más bien cuestiona la posibilidad de que entiendan "hasta la profundidad de sus consciencias su nueva condición social en la sociedad” (Gattini, 2008: 123).

Así, por ejemplo, en el capítulo catorce, dada la participación activa de Petra en las iglesias católicas de Valparaíso, son los otros pobladores de Valparaíso que hacen referencia "de forma soterrada, y a través de ingenuas personas, que Petra debía fundar en la ciudad una cofradía de pardos a la manera como existían en Santiago cuando el

7 Para un análisis más detallado la población afromestiza, véase el artículo de Fernanda Del Río Ortiz "Afrochilenos: Discursos oficiales en torno a los afromestizos en Chile" (2007). 
país era colonia española" (p. 176). El ebanista toma ese comentario con cierto recelo y lo atribuye a actitudes racistas de su entorno, en lugar de resaltar la importancia de las cofradías en las comunidades afromestizas. Además, es innegable que, al darle la libertad a Petra, el ebanista toma una actitud paternalista. Por ejemplo, le obliga a asistir a reuniones de su comunidad en contra de su propia voluntad y sin consultarle su opinión. Es significativo que la novela no revele las circunstancias de su matrimonio, aparte de que el ebanista la ama, y quiere asegurar su libertad. El lector, sin embargo, no conoce los deseos de Petra. De tal modo que el matrimonio con el ebanista se convierte en otro tipo de subyugación para Petra.

El largo viaje terrestre desde Buenos Aires hasta Valparaíso, pasando por los Andes, funciona como metáfora de la dificultad del camino hacia la libertad ${ }^{8}$. En Valparaíso somos testigos de la formación de una sociedad donde diversas etnias (en su mayoría ingleses y criollos) se relacionan entre sí en múltiples espacios sociales. El ebanista inglés trata de forjar un lugar donde vivir y ser parte de una nueva sociedad que acepte a su esposa negra. Sin embargo, aunque participan en algunas tertulias y parecen estar a gusto, la discriminación dificulta su inserción plena:

El ebanista con su esposa fueron invitados a las primeras [reuniones] que se organizaron, con la aguda reticencia de ella. También concurrieron algunas porteñas conocidas por los anfitriones. Él pensó que por fin lo ingleses avecindados en la ciudad lo reconocían socialmente y que, si estos pertenecían a una generación joven con una mentalidad más abierta, el futuro para ellos respecto a sus conciudadanos tendría la integración que se les había negado desde que llegaron a Valparaíso. (p. 151. El énfasis es nuestro)

El carpintero vive consciente del racismo soterrado entre los miembros de la sociedad porteña. Es más, incluso en el momento en que éste siente optimismo por una futura integración más plena en su sociedad, es consciente de sus limitaciones. De modo que la novela muestra estos diversos estratos sociales como espacios en disputa donde es posible negociar posicionamientos hegemónicos y con-

8 En realidad, la libertad está limitada sólo a las tres mujeres negras, los otros esclavos han sido vendidos en diferentes lugares (enviados a La Ciudad de los Reyes o a Santiago de Chile) y muchos mueren al atravesar los Andes. En este sentido, el subtítulo de la novela es engañoso: "Desde las lejanas costas del África al puerto de Valparaiso. Un viaje a la libertad y al amor." 
tra-hegemónicos. En una tercera reunión, Petra es víctima del acoso sexual por unos jóvenes comisionistas de finanzas de supuesta "mentalidad abierta":

Un grupo de ellos distrajo al ebanista con una conversación insulsa en un rincón del salón. De pronto, por intuición, se dio vuelta y vio como algunos muchachos ingleses manoseaban a Petra por encima de su vestido, en un acto insólito en su vida que la tomó desprevenida. (p. 152)

\section{$[\ldots]$}

Corrió hacia ella y de manera firme pero controlada abrió con sus largos brazos un espacio tan grande para dejarla al centro [...] sí capitán Rhods, gritaba hacia sus adentros, sí imbécil yo soy el perro blanco de esta mujer negra. (p. 153)

El pasaje arriba citado ejemplifica la dificultad que tiene la pareja para reclamar y afianzar un espacio de aceptación y reconocimiento social. En este y otros episodios, Petra es descrita como dócil y tímida. A pesar del significado de su nombre, no tiene carácter fuerte ni valor para defenderse a sí misma, creando, así, la imagen de una princesa elegante pero débil que requiere de un caballero (el ebanista) que la rescate. De ahí que este episodio es doblemente clave: por una parte, le permite al ebanista condenar las consecuencias de la esclavitud y de los estereotipos sobre la mujer negra como objeto sexual; por otra, le permite subvertir su posicionamiento en la jerarquía racializada de la que era testigo. Durante el medio pasaje ${ }^{9}$ y sus interacciones en el barco donde transportaban a las esclavas, el ebanista estaba consciente de que el capitán Rhods y los otros tripulantes lo juzgaban por proteger y tratar a las tres negras de un modo diferente a lo establecido y lo aceptable: "el capitán los miraba con mordaz desprecio" (p. 43).

\section{¿Cómo representar a las mujeres negras?: Petra, la princesa etíope "amordazada", y las peripecias del camino a la libertad}

Siguiendo en esta línea de análisis, veamos el papel de Petra y su función dentro de la novela para esclarecer algunas estrategias narrativas y discursivas que revelan una ideología racializada. Al estudiar la representación de los personajes negros en la literatura estadounidense, lo cual es aplicable a nuestra novela, Toni Morrison (1993)

9 Utilizo "el medio pasaje" en lugar de "el pasaje del medio" o "Middle Passage", por ser tal como lo nombra el autor en la novela. 
alega que "For both black and white American writers, in a wholly racialized society, there is no escape from racially inflected language, and the work writers do to unhobble the imagination from the demands of that language is complicated, and definitive" (p. 12-13).

Una lectura detenida de la representación de Petra nos presenta una visión romantizada de la princesa etíope. El ebanista inglés, al verla por vez primera queda embelesado y las descripciones de este encuentro, cargadas de sentimentalismo, hacen eco de las historias de amor presentes en las novelas románticas decimonónicas. Las primeras descripciones que tenemos de ella son las de una dama elegante y noble: "[e]lla era de rostro digno, con proporciones perfectas, sus alargados ojos, fina nariz y delgados labios estaban enmarcados por una amplia frente rodeada de sus cabellos tomados atrás, [...]" (p. 14. El énfasis es nuestro). Salta a la vista que la mujer es bella en la medida en que sus rasgos fenotípicos se aproximan a los ideales de belleza europeos. Y, como Nicolás Guillén, preguntamos por qué no podríamos decir su bella nariz y labios grandes ${ }^{10}$.

Además, observamos que los otros esclavos muestran deferencia hacia la dama "tan" (tostada-bronceada) creando, así, una jerarquía basada en una suerte de pigmentocracia: "[...] todas se inclinaban ante ella a modo de reverencia, sin decir palabra alguna. Era el silencioso reconocimiento a una autoridad o a un ser superior: un respeto ancestral a las jerarquías" (p. 26), y el ebanista, desde un primer momento, se niega a referirse a ella como negra. Por una parte, tenemos un narrador que nos relata la historia desde la perspectiva de un ebanista profundamente enamorado, quien está en contra de la esclavitud y el trato inhumano a los esclavos. Por otra parte, la manera en que el narrador opta por representar a las mujeres negras y el lenguaje que usa para describirlas revelan un discurso racializado:

Él, desde un principio, se refirió a las mujeres escoltas denominándolas, sin más, como "negras". A ella, en cambio, la definiría como "tan", es decir, tostada. El grupo mantenía casi siempre la misma disposición básica, la cual

\footnotetext{
10 Este pasaje contrasta con el poema de la costarricense Shirley Campbell titulado "Rotundamente negra", donde los versos: "Con mi boca/rotundamente grande, /y mi nariz/rotundamente hermosa", disienten con la descripción eurocéntrica de la belleza. Asimismo, el poema "¿Qué color?" de Nicolás Guillén, en referencia a Martin Luther King, cuestiona la asociación de lo blanco como lo bueno: "que alma tan blanca, dicen,/.../ Pero podría decirse de otro modo:/ Qué alma tan poderosa negra/ la del dulcísimo pastor./ .../¿Por qué no,/ por qué no iba a tener el alma negra/aquel heroico pastor?/ Negra como el carbón'(1998: 45).
} 
modificaba levemente según la dirección en que se movía o quien enfrentaba. Ella, alta y fina, siempre al medio, la mujer grande, anclada en su reposada seguridad, pegada a su izquierda y, a un paso más adelante a su derecha, la más pequeña, nerviosa, pronta a convertirse en una chispa inextinguible (p. 14).

Vale la pena señalar la duplicidad discursiva en esta descripción y en la caracterización de las mujeres esclavas. Es decir, la narración en sí manifiesta una pugna interna en la representación de las mujeres negras ya que el ebanista se refiere a las esclavas de Petra ("sin más como 'negras'. A ella [Petra] en cambio, la definiría como 'tan' ") ${ }^{11}$. Existe una suerte de tensión narrativa, de duelo entre la visión eurocéntrica del ebanista y su deseo de deshacerse de los presupuestos arraigados en dicha ideología. A lo largo de la novela, las denuncias en contra de la esclavitud, las injusticias sociales y el racismo (por boca del ebanista) se yuxtaponen con su deseo por crear jerarquías racializadas (el trato diferenciado a Petra). Dichos "deslices" dan cuenta de la dificultad de escaparse de lo que Morrison denomina lenguaje cargado (impregnado) de racismo (racially inflected language). Un ejemplo clave de lo expuesto sería el constante empeño del narrador en marcar su diferencia y separar a Petra de los otros esclavos negros. Las referencias a "la tan" o "la dama tan" se repiten veintinueve veces en la novela. Entonces, aunque no cosifica a Petra, sí objetiviza a las otras mujeres negras. Dicha objetivación sobresale en la representación de Naha, una de las acompañantes de Petra. El momento en que bajan del barco en Montevideo, los esclavos deben despojarse de sus ropas para ser expuestos a los clientes y sus futuros amos. En ese momento, Naha es descrita en estos términos:

[...] la más grande y vieja había engordado de manera especial: presentaba unas descomunales e impresionantes nalgas que harían reír a la marinería y, en general, a la gente vulgar. Redondas, amplias y extendidas hacia atrás, eran verdaderas mochilas prendidas por debajo de la cintura (p. 42).

Cabe notar la mirada colonial racializante que deshumaniza al otro. En la novela, los esclavos son descritos como "mercancía", "piezas negras", "cargamento de negros". Veamos el comentario de Foster, el

11 Aunque no es enfoque de nuestro análisis, cabe resaltar el fenómeno de la esclavitud dentro de la esclavitud. La "dama tan" es una princesa etíope quien ha sido capturada con sus dos esclavas, Naha y Sinaya, quienes la protegen de todo, hasta de ser violada. 
inglés "autorizado por el virrey para trasladar esclavos por territorios de España” (p. 51): “-Es ganado caro para arriar -decía Foster y continuaba-, pero no se puede carnear ni comer -terminando con una risotada" (p. 51). La actitud de Foster pone al descubierto ese proceso que, según Fanon, "Dehumanizes the native [...] it turns him into an animal. In fact, the terms the settler uses when he mentions the native are zoological terms" (1963:42). El colonizador/traficante de esclavos construye en su mente al otro como un ser "bárbaro/ inferior", y a su yo, como un ser "civilizado/superior" digno de emulación. La corporalización caricaturizada de Naha, arriba citada, es una prueba más de lo expuesto por Fanon. Es innegable que dicha mirada colonial se encuentra íntimamente ligada a la creación de la "otredad", un proceso que ha sido estudiado con amplitud y profundidad por Todorov en La conquista de América: la cuestión del otro ${ }^{12}$.

Se podría contraargumentar que la representación de Petra es, en términos generales, positiva ya que su personaje escapa a la cosificación en la novela. Por ejemplo, ella tiene nombre, mientras que el ebanista no, y recibe un trato respetuoso de parte de los otros esclavos. Pese a ello, Petra casi no tiene voz propia en la narrativa. Sólo la oímos repetir una palabra en dos ocasiones en toda la novela: "Tana, Tana, Tana", al ver la bahía de Valparaíso, por su semejanza con el lago Tana, en Etiopía:

Al mismo tiempo, sintió a alguien hablando a su lado. Decía: Tana, Tana, Tana, mirando hacia el horizonte. Era ella. El inglés entonces creyó estaba repitiendo, mal balbuceada, la palabra "tan" con la cual se refería a ella, aunque no se acordaba ni imaginaba en qué momento la había pronunciado en su presencia (p. 95).

12 Aunque Todorov (1998) se refiere al encuentro de Colón con los nativos, el proceso de creación de la alteridad es aplicable a otras relaciones entre colonizador/ colonizado: "La actitud de Colón respecto a los indios destaca en la manera que tiene de percibirlos. Se podría distinguir en ella dos componentes, que se vuelven a encontrar en el siglo siguiente y, prácticamente, hasta nuestros días en la relación de todo colonizador con el colonizado. 0 bien piensa en los indios (aunque no utilice estos términos) como seres humanos completos, que tienen los mismos derechos que él, pero entonces no sólo los ve iguales, sino también idénticos, y esta conducta desemboca en el asimilacionismo, en la proyección de los propios valores en los demás. 0 bien parte de la diferencia, pero esta se traduce inmediatamente en términos de superioridad e inferioridad (en su caso evidentemente los inferiores son los indios): se niega la existencia de una sustancia humana realmente otra, que pueda no ser un simple estado imperfecto de uno mismo" (p. 50). 


\section{$[\ldots]$}

La dama "tan", apenas ingresada a la casa, se apoyó en su recién barnizada baranda y mirando ese horizonte, tal cuando lo viera por primera vez, de nuevo dijo, ahora en voz alta y clara:

-Tana, Tana, Tana (p. 120).

Lo poco que sabemos de Petra lo aprendemos por medio de Tonio y el padre jesuita Juan Gonzales. Finalmente, la historia de su vida está mediada por el ebanista; es decir, el lector nunca tiene la oportunidad de oír a Petra contarnos su vida directamente. Como Gayatri Spivak, llegamos a la conclusión de que el relato mediatizado no le permite al subalterno (Petra) tomar la palabra. Asimismo, a juicio de Morrison, el personaje negro (en las narrativas en general) se encuentra amordazado: "What became transparent were the self-evident ways that Americans choose to talk about themselves through and within a sometimes allegorical, sometimes metaphorical, but always chocked representation of an Africanist presence." (p. 17).

Es de notar la dificultad y las trampas que existen para el escritor que quiere tratar de deshacerse de un aparato epistemológico eurocéntrico y de una ideología racializada. El narrador tiene la oportunidad de dejarle hablar a Petra directamente, y, de tal forma, darle el control de su historia, pero éste no aprovecha esos instantes:

Al carpintero, si bien estaba agradecido de don Juan Gonzales, le hubiera gustado haber escuchado la historia de labios de su propia esposa. Pero él tampoco había mostrado interés en sus orígenes, para no presionarla, y en consecuencia, no le había hecho preguntas. Cuando le habló a Petra sobre la reciente conversación con el sacerdote, ella le completó algunos datos y le corrigió otros. Además, le reveló las circunstancias de cómo la capturaron. El episodio no formó parte de la conversación con el padre Juan (p. 133. El énfasis es nuestro).

El hecho de que Petra "le completó algunos datos y le corrigió otros", es clave, ya que le da cierto control narrativo a ella. Sin embargo, los lectores nunca sabrán el contenido de esa narración, lo cual socava su control y la "amordaza" nuevamente. Una vez más, se evidencia esa tensión narrativa que revela un narrador con simpatía paternalista por el negro y su posicionamiento social, pero que se encuentra limitado e influenciado por un registro e imaginario racializados. Vale la pena reiterar que la novela está narrada desde la perspectiva del ebanista inglés, por eso la narración muestra cierta empatía por 
los esclavos; pero al mismo tiempo, el narrador revela sus propios prejuicios por la manera en que describe y representa a las mujeres. Por otra parte, existen indicios de que el narrador podría estar relatando la historia sirviéndose de los apuntes del "cuaderno" del ebanista, ya que existen numerosas referencias, a lo largo de la novela, a sus notas sobre los eventos de la travesía y sus recuerdos. Este hecho, a veces, desdibuja la clara demarcación entre la voz narrador y la del ebanista y crea esa tensión narrativa a la que hemos aludido anteriormente ${ }^{13}$. De cualquier modo, el discurso narrativo pone en evidencia un narrador que sufre de una "imaginación colonizada" (Franco, 1975: 18) que influye en los modos de conocer, de producir imágenes y símbolos, y los modos de significación que presenciamos en la narrativa. Los efectos de esa mentalidad colonizada se manifiestan en la vacilación, las discrepancias y las ambivalencias discursivas anteriormente destacadas, que dan cuenta de la dificultad de romper la profunda imbricación entre la cultura, el lenguaje y la ideología. Gattini crea, así, con gran maestría, un personaje que refleja su momento histórico; es decir, uno que se encuentra a caballo entre dos ideologías en disputa: la del esclavista (colonial/imperialista) y la del anti esclavista (poscolonial/independentista).

A través de los comentarios de personajes como el ebanista inglés, el cirujano Rovira y el guía Foster, la novela capta las complejidades etno-históricas y políticas de una sociedad en formación y nos acerca a las "otras" historias omitidas por la historia oficial. Dicha omisión ha posicionado a los afrochilenos en una condición de invisibilidad, negándoles un papel activo como sujetos productores de cultura y partícipes en el devenir histórico nacional. Para tratar el tema de la esclavitud en el periodo colonial, Gattini se sirve de la novela histórica que le permite realizar un proceso de revisión historiográfíca que recupera la historia olvidada del afrochileno para inscribirla en los registros oficiales y legitimar su contribución a la formación de una identidad nacional. Gattini, al enmarcar su novela entre 18071837 (momento clave por la abolición de la trata inglesa); al resaltar fechas claves como 1811 y 1823 (libertad de vientre/abolición de la esclavitud); al enfocarse en las luchas independentistas en Chile (subrayando el protagonismo de los afrochilenos en el "Batallón de los pardos"), reinscribe en la memoria histórica chilena la presencia de una población pluriétnica y multicultural que influyó poderosamente en la formación de la nación. De tal modo, nos invita a cuestionar

13 Veánse las múltiples referencias al cuaderno del ebanista y las referencias a sus anotaciones: El barco de ébano pp.30, 31, 76, 82 ,98, 102, 123, 139, 109, 147, 166, $181,185$. 
lo que Jean-Paul Zúniga ha descrito como la "estrepitosa ausencia" de la presencia afrochilena en la memoria y el mapa socio-geográfico y cultural chileno (2009: 81).

Según Jelin, los procesos de recordar y olvidar "no ocurren en individuos aislados sino insertos en redes de relaciones sociales, en grupos, instituciones y culturas" (2002: 19). Es decir que las instituciones juegan un papel importante en los procesos de inserción y recuperación de la(s) historia(s) en la memoria colectiva ${ }^{14}$. En este sentido, la obra de Gattini, invita a la sociedad chilena contemporánea a escuchar a esas voces silenciadas, y reinscribir en la historia oficial a todos los diferentes actores sociales. Actores que, en la actualidad, reclaman ser reconocidos como miembros de su sociedad con plenitud de derechos, y que buscan desmantelar del imaginario histórico nacional los estereotipos sobre los afrochilenos, forjados a partir del siglo XIX. Del Río Ortiz denuncia el hecho de que el gobierno chileno aún no haya reconocido a los afrodescendientes como etnia, y que el proyecto presentado al Congreso para dicho reconocimiento, en 2009, recién se haya aprobado en marzo del 2019. A juicio de Del Río Ortiz, esto se debe a políticas de olvido y silencio que han primado basados en la supuesta "irrelevancia histórica de la población africana y afromestiza" (p. 2) ${ }^{15}$.

\section{Conclusión}

Hasta el momento, Chile no ha logrado articular un concepto de nación que incluya los múltiples grupos étnicos; de hecho, las minorías afromestizas no han sido plenamente insertadas en los discursos

14 En un estudio muy sugerente, Silvia Valero (2015) analiza las nuevas narrativas del siglo XXI que incorporan la temática de lo "afro" ("desde adentro" y "desde afuera") impulsadas por políticas nacionales e internacionales que han priorizado el enfoque en dicho tema. Como consecuencia, Valero ha notado que en ese afán de incorporar la temática "afro", a veces, se sacrifica la calidad estético-literaria: "[...] en su afán por 'sensiblizar y hacer tomar consciencia', vacila, como lo adelanté, entre el relato ficcional y el histórico, por lo cual por momentos, el fraseo narrativo pierde el ritmo novelesco para acercarse al historiográfico" (p. 565). Creo que la novela de Gattini presenta los mismos retos, en cuanto al sacrificio de la calidad estético-literaria. Sin embargo, de momento no se podría aseverar que haya una carrera en incorporar la temática afro en la narrativa chilena actual. No tenemos conocimiento de otra novela que trate lo "afro", lo cual no significa que no exista. No obstante, el análisis de Valero es de suma importancia para esclarecer dichas tendencias en el futuro.

$15 \mathrm{Al}$ momento de completar este trabajo, supimos que el proyecto de ley para dar reconocimiento legal a los afrochilenos ha sido "aprobado [el 7 de marzo del 2019] 
en torno a la identidad nacional ya que, según Cussen, la ideología decimonónica no permitía un discurso de esclavitud, porque socavaría el mito de un país que se veía libre de esta práctica aberrante, y del cual sentía orgullo nacional. Se había forjado la idea de un espacio de resistencia que luchaba contra la ocupación española (resistencia mapuche), un mito que diseminaba la idea de que en Chile no se permitía tener esclavos, entonces, aceptar la participación chilena en la trata, no era consecuente con la idea que se tenía de la nación como un país progresista. Estos imaginarios nacionales han contribuido a crear e implementar políticas decisivas de omisión que han tenido un impacto directo en la exclusión de algunos grupos étnicos en la forja de la nación.

A la luz de esta realidad, y pese a las contradicciones, vacilaciones, y paradojas notadas en el tejido narrativo, la novela de Gattini es de importancia capital porque representa una tentativa de revisión historiográfica y pone de relieve la imperante necesidad de recuperar la memoria perdida y/o negada, un hecho largamente postergado por la historiografía local. Los afrochilenos han permanecido en los márgenes de la historia, a pesar de que han sido, y siguen siendo, una parte fundamental de la heterogeneidad nacional, como lo demuestran los estudios recientes de Cristian Báez, Marta Salgado y María Contreras. No cabe duda de que Ricardo Gattini rompe con la tradición literaria y marca un hito en la narrativa chilena por el hecho de tratar un tema tácitamente velado.

\section{Bibliografía}

Aguirre, C. (1993). Agentes de su propia libertad: Los esclavos de Lima y la desintegración de la esclavitud 1821-1854. Lima: Fondo Editorial de la Pontificia Universidad Católica del Perú.

Báez, C. (2010). Lumbanga: memorias orales de la cultura afrochilena. Arica: Herco Editores.

Barrenechea, P. (2015). Patrimonio, narrativas racializadas y políticas de la memoria. Abordaje a un manuscrito afrodescendiente en el Valle de Azapa. Estudios Avanzados IDEA-USACH, (23), $15-31$.

por la Cámara de Diputados, por lo que ya está en condiciones de pasar al Ejecutivo para su promulgación como ley de la República" (Menares Velásquez). Véase el blog de la ONG Oro Negro: http://ong-oronegro.blogspot.com/ 
Cussen, C. (2009). La ardua tarea de ser libre: Manumisión e integración social de los negros en Santiago de Chile colonial. En C. Cussen (Ed.), Huellas de África en América: Perspectivas para Chile (pp. 109-136). Santiago: Editorial Universitaria.

Contreras Segura, M. T. (2013). Una ausencia aparente. Africanos y afromestizos en Valparaíso tardocolonial. 1170-1820. Revista de Historia Social y de Mentalidades, 17(2), 105-139.

Del Río, F. (2010). Afrochilenos: Discursos oficiales en torno a los afromestizos en Chile. Actas de las IV Jornadas Experiencias de la Diversidad. CEDCU, Facultad de Humanidades y Artes, Universidad Nacional de Rosario.

Fanon, F. (1963). The Wretched of the Earth. Trans. Constance Farrington. New York: Grove Press.

Franco, J. (1975). Historia de la literatura latinoamericana a partir de la Independencia. [Traducción Carlos Pujol]. Barcelona: Ariel.

Gattini, R. (2008). El barco de ébano. Santiago de Chile: Random House Mondadori S.A.

Guillén, N. (1998). Sóngoro Consongo y otros poemas. Madrid: Alianza Editorial.

Jelin, E. (2002). Los trabajos de la memoria. Buenos Aires: Siglo XXI Editores.

Márquez Macías, R. \& Candau Chacón, M. L. (2016). Las otras mujeres de América: las esclavas negras en tiempos de la Colonia. Un estudio a través de la correspondencia privada. Visitas al patio, (10), 75-92.

Mellafe, R. (1959). La introducción de la esclavitud negra en Chile. Tráfico y rutas. Santiago: Ediciones de la Universidad de Chile.

Menares Velásquez, F. (2019). Congreso despacha proyecto que reconoce al pueblo afrodescendiente. Politika. Recuperado de en http://www.politika.cl/2019/03/07/congreso-despacha-proyecto-que-reconoce-al-pueblo-afrodescendiente-chileno/

Morrison, T. (1993). Playing in the Dark: Whiteness and the Literary Imagination. New York: Vintage Books. 
Salgado, M. (2012). Afrochilenos: una historia oculta. Arica: Herco Editores.

San Martin, W. (2007). Esclavitud, libertades y resistencias. Hacia una propuesta integrativa a las condiciones de la negritud en Chile, S. XVIII. Revista Summa Historiae, 2(2), 195-209.

Spivak, Gayatri C. (1988). Can the Subaltern Speak? En C. Nelson and L. Grossberg (Eds.), Marxism and the Interpretation of Culture (pp. 271-314). London: Macmillan.

Todorov, T. \& Botton Burlá, F. (1998). La conquista de América: la cuestión del otro. Madrid: Siglo XXI.

Valero, S. (2015). Afroepistemología y sensibilización en las narrativas históricas afrodescendientes del siglo XXI. En S. Valero y A. Campos García (Ed.), Identidades políticas en tiempos de Afrodescendencia: Autoidentificación, ancestralidad, visibilidad y derechos (pp. 557-575). Buenos Aires: Ediciones Corregidor.

Zúñiga, J-P. (2009). Huellas de una ausencia. Auge y evolución de la población africana en Chile: apuntes para una encuesta. En C. Cussen (Ed.), Huellas de África en América: Perspectivas para Chile (pp. 81-108). Santiago: Editorial Universitaria. 